\title{
Truthmakers (are indexed combinations)
}

\author{
Wolfgang Freitag \\ Department of Philosophy, University of Konstanz
}

\begin{abstract}
My aim is to show that theories which try to construct truthmakers out of objects and properties/relations alone are not tenable: The Frege-Wittgenstein idea of incompleteness does not yield truthmakers. Armstrong's theory of partial identity and the theory of moments, i.e., of non-transferable properties, yield truthmakers, but these theories have counter-intuitive consequences. I conclude that the notion of a truthmaker makes ontological demands beyond objects and properties/relations and propose that truthmakers are exemplification relations which are necessarily tied to objects and properties/relations.
\end{abstract}

Keywords: Bradley's regress, truthmakers, facts

\section{Introduction}

The proposition $<$ the earth is a globe $>^{1}$ is true. If it were false, the world would look very differently. A world in which a certain proposition is true is different from a world in which this proposition is false. The difference between the truth and the falsity of a proposition reflects an ontological difference. The investigation in truthmakers is the attempt to give an account of this ontological difference.

There has been a steadily intensified debate on truthmakers, since K. Mulligan, P. Simons, and B. Smith wrote their paper on this topic in 1984. My aim is to give a systematic overview over prominent options, to show that and why they are ultimately unsatisfactory, and, finally, to make a proposal of my own: truthmakers are exemplification relations which are necessarily tied to objects and properties/relations; in my terminology, truthmakers are "indexed combinations." Let me begin, however, by explaining the nature of the problem.

Corresponding author's address: Wolfgang Freitag, Somestreet xx, Sometown, Somedistrict, Somecountry. Email: wolfgang.freitag@uni-konstanz.de.

1 I follow Paul Horwich (1998) in signifying the name of a proposition by this use of brackets. 


\section{The argument for truthmakers}

I shall start with an argument for truthmakers. Some propositions are false. Some propositions are true. Consider the proposition $<$ the pen is black $>$. It is in fact true, though it could have been false. The truth-value of a proposition is not an arbitrary matter; it is determined by something. Whether it is true or false is grounded in an ontological difference. With the vast majority of the literature, I shall assume that the ontological difference is an ontological addition in the case of truth; truth is established by an ontological addition. Thus, I assume that the truth of a proposition is determined by something that exists. ${ }^{2}$ It follows that there exists something which determines that the proposition <the pen is black $>$ is true. Truth is ontologically grounded. ${ }^{3}$ The philosophical term for this ontological ground is 'truthmaker'.

The label 'truthmaker' is a misnomer, because it suggests that the truthmaker plays a causal role in the genesis of the truth considered-much as in the case of the troublemaker, who plays a causal role in the genesis of the trouble considered. However, although truthmakers cause trouble, they do not cause truth. It would be better to call truthmakers 'truth-determinants'those things in virtue of which a truth is true. But having freed the term from possibly misleading connotations, I shall stick to the established usage.

That there are truthmakers in the minimal sense required by my argument above is, I think, undisputed. The trouble is to find out what they are. This is the truthmaker problem.

In the discussion, I will concentrate on truthmakers for contingent, positive, descriptive, predicative, nonreflexive propositions, propositions of the form ' $a$ is $F$. Whether we have to account for the other kinds of propositions in terms of truthmakers at all, and whether we need the same kind of truthmaker for them, shall not be a matter of the present paper.

\section{Specifying the truthmaker problem}

Since there are true propositions, truthmakers do exist. But where shall we look for them? I assume that propositions are entities which represent (like sentences and judgments are), i.e., they are about something. I shall also assume that a proposition represents extrapropositional reality ${ }^{4}$ and that a

${ }^{2}$ Whether its falsity is also determined by something that exists, I shall not discuss in detail here. Usually, philosophers try to do without falsemakers and determine falsity by the lack of truthmakers. I consider that to be the right strategy, but cannot discuss the difficulties it must solve in order to be successful.

3 See also (Rodriguez-Pereyra 2005, 22).

${ }^{4}$ I shall hence omit the complication that a proposition may be about itself or other propositions. 
truthmaker has the same ontological status as whatever the proposition represents. From this I conclude that truthmakers are part of the extrapropositional reality. The truthmaker of $<$ the pen is black $>$ is not itself part of this or any other proposition.

This expresses a view of minimal realism concerning truthmakers. Truthmakers so construed, however, do not commit us to a strong form of realism -the view that there is an extramental reality. It may well be that truthmakers are mental entities. Although I shall adopt a naïve realist standpoint for the purposes of this paper, idealism in the sense of there being no mindindependent world is also compatible with my views on truthmakers.

The upshot of my argumentation may be stated as the "truthmaker principle":

(TM) For proposition $<p>$ to be true, there must be a part of extrapropositional reality which is a truthmaker for $\langle p\rangle$.

(TM) is not undisputed. One type of objection is based on a certain understanding of Alfred Tarski's conception of truth. Here the objection in the words of Julian Dodd: 5

Why must every (contingent, non-negative) truth be made true by something? [...] As we have seen, Tarski-style truth-theories explain how sentences come to be true without positing truthmakers: ' $a$ is $F$ ' is true just in case the object referred to by ' $a$ ' satisfies the predicate 'is $F$. As yet there is no reason to suppose that the world must contain either the universal $F$ or the state of affairs of a's being F. (Dodd 200o, 10)

In a footnote, Dodd adds:

Here there is ontological commitment to $a$ only, and not to a truthmaker. (Dodd 2000, fn. 26, referring back to fn. 9)

I fail to see its relevance as an objection to (TM). Tarski-style theories, cited by Dodd, do not deny the need for truthmakers. Rather they propose a specific theory thereof, namely that particulars (or-we might generalise his case-sequences of such) are the truthmakers. Hence, this "objection" does nothing to discredit the need for truthmakers. At most it discredits conceptions which postulate truthmakers over and above particular objects.

But are particular objects (or sequences of objects) truthmakers? In Tarski-style theories, objects (or sequences of such) are sufficient for the satisfaction of an open formula. This is correct, yet also irrelevant. Satisfaction

5 Dodd criticises a slightly different version of (TM). The difference is not essential for present purposes. 
of open formulas does not result in truthmaking of propositions! The pen alone does not make the proposition $<$ the pen is black $>$ true. It may be that the very same pen exists without this proposition being true-e.g., when the pen is green.

At this point it may be useful to introduce the distinction between "thin" and "thick" particulars, which I take from David Armstrong. Thin particulars are particulars "in abstraction from [their] properties" (Armstrong 1997, 123). Thick particulars are particulars "taken along with all and only the [particulars'] non-relational properties" (Armstrong 1997, 124). Thus the pen $q u a$ thin particular is the pen alone without any of its properties, especially without its property of being black. The pen together with its non-relational properties, e.g., its colour, is a thick particular.

The proponents of a Tarski-style theory have thin particulars in mind as the things which satisfy. But the pen qua thin particular is not a truthmaker for the proposition <the pen is black>. Only the pen qua thick particular is such a truthmaker. With the thick particular itself, however, we already have a fact (or a set of facts). ${ }^{6}$ As such, the thick particular is the target of our explanation and must hence not be used as its beginning.

In a first attempt to make the thin particular thick, the obvious move would be to involve not only the thin particular (the pen) as truthmaker, but also the property, i.e., the property of being black. In the case at hand, we would not only need $a$, but also $F$. Does not the existence of (thin) particulars and properties suffice for truthmakers? No. It may well be that both, the particular $a$ and the property $F$, exist without $a$ 's being $F$. Particular $a$ and property $F$ alone do not suffice as truthmakers for ' $a$ is $F$, because it may be that they both exist but are not linked in the appropriate way. It may be that this pen and blackness both exist, but that this pen is not black.

The line of reasoning showing that neither the particular nor the particular and the property together are by themselves truthmakers is based on the necessitation principle putting a crucial constraint on candidates for truthmaking:

(NP) In all possible worlds in which the truthmaker for the proposition $<p>$ exists $\left\langle p>\right.$ is true. $^{7}$

The particular, the pen, does not necessitate the truth of $<$ the pen is black $>$ or any other true contingent predicative proposition; nor does the aggregate of the pen and blackness. What is demanded is not an aggregate of entities (particular and property) but their unity. The truthmaker problem is the

${ }^{6}$ See (Armstrong 1997, 126). Armstrong uses the expression 'state of affairs' instead of 'fact'.

7 Armstrong (2004b, 5-6) calls this 'truthmaker-necessitarianism', a label which I find unnecessarily cumbersome. 
problem of giving an ontological explanation for the connection between object and property, of $a$ 's having the property $F$, of $a$ 's being $F$.

Before I start to discuss the responses to the truthmaker problem, I shall introduce some terminology. In each specific case I have a deeper ontological motivation for this terminology. Since this deeper ontological motivation will not play any significant role for my arguments, I will only mention and not discuss it. The point of introducing the terminology is to make the theories to be discussed more easily comparable. I hope this will become clear in the cases at hand.

The ontological explanation of a's being $F$ has usually been transferred to an ontological relation called 'instantiation' or 'exemplification. ${ }^{8}$ I shall instead speak of 'combination'. The advantage of using the word 'combination' over using the traditional words 'instantiation' and 'exemplification' lies in this: 'Instantiation' and 'exemplification' denote asymmetric relations and hence presuppose a judgment on the nature of the relation involved. 'Combination', however, denotes a relation that may be symmetric and hence is ontologically neutral. For the purpose of this paper, I shall indeed assume that this relation is symmetric, although I shall not argue for this view here. This assumption has no argumentative but only an expository function.

The elements to be related by the combination relation will be called 'secondary contents. This term covers both particulars and properties (or relations). Both $a$ and $F$, this pen and blackness, are secondary contents. My terminology is neutral on the question whether we have to divide the contents of the world in two categories, that of particulars and that of properties. I think this neutrality is welcome, since the alleged distinction between particulars and properties-resulting in the problem of universals-seems to be motivated by the distinction between particulars and universals, which arguably cannot, upon reflection, be maintained. ${ }^{9}$ For the purposes of this paper, I shall assume that secondary contents are ontologically on a par. ${ }^{10}$ Again this has expository function, only.

The term 'primary content' denotes possible combinations of secondary

8 These are the more modern labels for Plato's 'methexis'.

9 I basically share Fraser MacBride's (2005) scepticism on the alleged distinction between individuals and universals, which underlies that between particulars and properties. My views have evolved independently and have been presented in my dissertation (Freitag 2005).

${ }^{10}$ Nevertheless there are differences between secondary contents. They have different "forms", different possibilities to combine into obtaining primary contents. The form of this pen is different from the form of, say, this electron. This pen can combine with blackness, this electron cannot. This electron and blackness do not compose a primary content, a possible fact. In this way, forms of secondary contents determine ontological possibilities, the primary contents, by determining possible combinations. 
contents. The possibilities of the pen's being green and the pen's being black are such primary contents. 'Obtaining primary content', finally, denotes those primary contents which actually obtain. These are the (elementary) facts. The pen's being black is, and the pen's being green is not, an obtaining primary content.

In this new terminology, the truthmaker problem is the problem of giving an account for the obtaining of primary contents, of giving an ontological explanation of what determines that primary contents obtain.

\section{The demand for a combination relation and the Bradley regress}

I shall now discuss several proposals which purport to explain obtaining primary contents. We face the challenge of explaining how an object has a certain property, the challenge of explaining what makes one secondary content be combined with another. The secondary contents by themselves are not sufficient for the making true of predicative propositions. So let us make the obvious move and involve a combination relation besides these secondary contents. Does the set of the combination relation and the two secondary contents to be combined finally settle our problems? Arguably not. For it may be that all of these objects exist without the combination relation holding between the respective secondary contents. Let me show this with the following example:

If object $a$ and property $F$ are to be combined into an obtaining primary content by some combination relation-call it ' $\mathrm{C}$ ' - then it is hard to see how this relation $C$ could not itself be part of our ontology. But if the relation $C$ is to relate $a$ and $F$, then its seems that $a$ and $F$ must be combined with $\mathrm{C}$, thus calling for a further combination relation between these three entities. Now the same style of argument can be reiterated, starting an infinite regress of ever more combination relations. This is the essence of the Bradley regress. ${ }^{11}$ The Bradley regress is based on the following individually necessary and jointly sufficient principles:

(C1) Whenever entities, e.g., secondary contents, are combined, then there exists a further entity, which combines the entities to be combined.

(C2) Whenever there is an entity which combines entities, it is also combined with the entities it combines.

${ }^{11}$ Actually, Bradley discusses the regress solely for the combination of objects and relations, not for combination in general. But as most contemporary philosophers do, I shall use the term 'Bradley regress' for this generalised version of the problem. I should also note that the regress has been known at least since Plato's Parmenides. 
The traditional account of combination naturally subscribes to $\left(\mathrm{C}_{1}\right)$ and seems to be forced to $\left(\mathrm{C}_{2}\right)$. But then the Bradley regress, the regress of ever more combination relations, is inevitable.

There are several strategies for dealing with the Bradley regress. Some authors acknowledge the regress, but assume it to be harmless. One of them is Armstrong in A World of States of Affairs:

It is often convenient to talk about instantiation, but states of affairs come first. If this is a 'fundamental tie', required by relations as much as by properties, then so be it. [...] Even if a 'relation' is conceded, the regress is harmless. The thing to notice is that, while the step from constituents to states of affairs is a contingent one, all the further steps in the suggested regress follow necessarily. [...] May it not be argued that the sole truthmaker for each step in the regress after the first (the introduction of the fundamental tie) is nothing more than the original state of affairs? Many truths if you like, but only the one truthmaker. A natural comparison is with the truth regress. (Armstrong 1997, 118119)

Since Armstrong himself has given up this view himself, I shall not further discuss it here. Suffice it to say that most philosophers, e.g., Wittgenstein, Mulligan et al., and Armstrong in a more recent book (Armstrong 2004b), think the regress to be pernicious and hence try to avoid it altogether. One strategy is to adopt $\left(\mathrm{C}_{1}\right)$ but deny $\left(\mathrm{C}_{2}\right)$. Peter Strawson (1959, ch. 5, sect. 2 and 3) speaks of "non-relational ties"-without, however, explaining how there can be such things. ${ }^{12}$ My own theory will adopt Strawson's strategy but also attempt to give an explanation of how a "tie" may be "non-relational". Let me prepare the ground for my own view, however, by first discussing the most prominent strategy to avoid the regress: the strategy of denying $\left(\mathrm{C}_{1}\right)$.

\section{Wittgenstein and incomplete secondary contents}

One of the earliest attempts in this direction is Ludwig Wittgenstein's in the Tractatus Logico-Philosophicus Wittgenstein (1922). Central to his theory is the notion of incompleteness, which he borrows from Gottlob Frege. Frege (1994), we recall, claims there to be a distinction between concepts and objects in the following sense: objects are saturated, complete entities, while

${ }^{12}$ Actually, it is not quite clear that Strawson adopts (C1). He says: "Something analogous to Bradley's argument against the reality of relations may be used, not indeed to show that relations are unreal, but to show that such assertible links [i.e., non-relational ties; W. F.] between terms as these [i.e., secondary contents, W. F.] are not to be construed as ordinary relations" (Strawson 1959, 167). This may be taken to mean that these non-relational ties are unreal, nonexistent, and hence that $(\mathrm{C} 1)$ is false. The question would then be how unreal things could be able to tie real terms together. So I prefer to interpret Strawson as affirming $\left(\mathrm{C}_{1}\right)$ and denying $\left(\mathrm{C}_{2}\right)$. 
concepts are unsaturated, incomplete. Concepts have, so to speak, a gapa gap which may be filled by objects. The incompleteness of concepts is marked by Frege with the bracket notation, as, e.g., in ' $F()$ '. This notation signals in a pictorial way the idea of incompleteness, besides marking concepts as forming a special kind of functions.

Wittgenstein takes the idea of incompleteness and generalises its application. For him, all secondary contents-objects and properties alike-are incomplete. Secondary contents are completed only via their gaps' being filled by other secondary contents. ${ }^{13}$ Together with the idea that incomplete entities cannot exist by themselves this yields the position that secondary contents cannot exist without their respective "gaps" being filled by other secondary contents. Thus no secondary content can exist on its own; every secondary content needs to be tied to other secondary contents. Secondary contents tied together, however, yield facts, obtaining primary contents. The idea that secondary contents are incomplete results in the view that the world consists of obtaining primary contents only. As Wittgenstein says in traditional terminology:

The world is the totality of facts, not of objects. (Wittgenstein 1922, 1.1)

That Wittgenstein refers to the incompleteness of secondary contents in the explanation of obtaining primary contents can be gathered from the following statement:

In the atomic fact objects hang one in another, like the links of a chain.

(Wittgenstein 1922, 2.03)

Wittgenstein explains this as follows:

The meaning is that there isn't anything third [in an atomic fact comprising two objects] that connects the links but that the links themselves make connexion with one another. (Letter to C. K. Ogden, dated 23.04.1922; Wittgenstein 1973, 23)

The constituents of atomic facts are my secondary contents. As secondary contents they are arguments and in turn have argument places themselves. The characteristic of having argument places may be portrayed, following Frege, with brackets indicating a gap in the secondary content. Thus, all secondary contents can be represented by expressions of the form ' $x()^{\prime} \cdot{ }^{14}$

${ }^{13}$ Thus I consider Wittgenstein to be the first philosopher to reject the traditional distinction between individuals and universals. Frank Ramsey, who is often cited as the originator of the attack on this distinction, may have inherited his ontological views from Wittgenstein, by whom he was very much influenced.

${ }^{14}$ I ignore here the complication that secondary contents might have several gaps. 
We can write ' $a()$ ' instead of ' $a$ ', and ' $F()$ ' instead of ' $F$ '. (Let us stipulate that the relative position of brackets to letter does not play a role. Instead of ' $a()$ ', we could also write ' ()$a$ ', instead of ' $F()$ ', we could write '( $) F$ '.)

The obtaining primary content-the fact-that $a$ is $F$ is nothing but the mutual completion of the respective secondary contents, i.e., $(a)(F)$ (or, equivalently, $(F)(a))$. One secondary content fills the gap of another secondary content, as one member in a chain hangs in another. The notation of obtaining primary contents in the form ' $(a)(F)$ ', indicating that each secondary content fills the gap of the other, probably provides the closest logical analogue to Wittgenstein's chain metaphor.

The Frege-Wittgenstein idea of incompleteness, together with the claim that there are no incomplete objects, necessitates that each secondary content is tied to another secondary content. Since there is no combining entity, condition $\left(\mathrm{C}_{1}\right)$ is rejected. We have combination between secondary contents without there being a combinator. The Bradley regress does not get started at all.

This was the theory; now to its criticism. Although the reference to incompleteness looks promising, it is instructive to see why it does not do the trick. Consider the situation in which there are exactly four incomplete secondary contents, objects $a$ and $b$ and properties $F$ and $G$. If we assume that both $\mathrm{a}$ and $\mathrm{b}$ individually combine with exactly one of the properties $F$ and $G$, and with nothing else, and if we assume that both $F$ and $G$ individually combine with exactly one of the objects $a$ and $b$, and with nothing else, then two situations are possible:

$\mathrm{W}_{1}: a$ is $F$ and $b$ is $G$. Or, in the chain-notation: $(a)(F)$ and $(b)(G)$.

$\mathrm{W}_{2}: a$ is $G$ and $b$ is $F$. In the chain-notation: $(a)(G)$ and $(b)(F)$.

Both situations comprise exactly the same material, the same incomplete secondary contents. Furthermore, no secondary content stands alone. Hence, there are no incomplete things. Both of the Wittgenstein assumptions are fulfilled. Still, the situations differ; they comprise different obtaining primary contents. Different propositions are true in these possible situations. The proposition $<a$ is $F>$ is true in $\mathrm{W}_{1}$, while it is false in $\mathrm{W}_{2}$. But this means that the mere existence of incomplete secondary contents, e.g., of $a$ and $F$, does not necessitate the truth of a predicative proposition, e.g., of $<a$ is $F>$. Secondary contents alone (or sets of them) do not satisfy the constraints posed by (NP). So, incomplete secondary contents are not sufficient for truthmaking.

The incompleteness of secondary contents determines merely that the world consists only of obtaining primary contents, of facts. It does not de- 
termine which primary contents actually obtain, and hence neither which truths there are. As a recent author sums up this criticism:

Even if $a$ and F-ness cannot exist except in some state of affairs or other, there is nothing in the nature of $a$ and nothing in the nature of F-ness to require that they combine with each other to form a's being F. (Valicella 2000, 238)

The Frege-Wittgenstein reference to incompleteness does not yield a satisfactory answer to the truthmaker problem. ${ }^{15}$

\section{Armstrong and partial identity}

David Armstrong, who has done much to popularise the quest for truthmakers, has given several different treatments of the topic. For simplicity's sake, I shall confine myself to his latest ideas. He writes:

I have had a change of heart about the instantiation of universals. In previous work I conceived of the instantiation as a matter of contingent connection of particulars with universals. New work by Donald Baxter $[\ldots]$ has made me think that the link is necessary. [...] I have been convinced by him that what is involved in a particular instantiating a property-universal is a partial identity of the particular and universal involved. [...] This in turn has led me to hold that instantiation is not contingent but necessary. (Armstrong 2004b, 46-47)

According to this new development, predication is supposed to be necessary. If $a$ is $F$, then $a$ is necessarily $F$. The existence of $a$ suffices for $a$ 's being $F$. Whenever $a$ exists, $a$ is $F$. We could also say that $F$ is constitutive of $a$. I shall say that $a$ is indexed to $F$ and express this by using the notation

${ }^{15}$ In the main text, I assume that Wittgenstein actually wants to solve the truthmaker problem by reference to incompleteness of secondary contents. Although I think this is the most plausible interpretation, all things considered, there is also another possibility: that Wittgenstein adduces the notion of incompleteness, not to explain obtaining primary contents, but to explain primary contents simpliciter. Since incompleteness is used to explain what Wittgenstein calls 'Sachverhalte', the matter hinges on how to understand this term. In the beginning of the Tractatus it seems to be used in the sense of 'atomic fact' (i.e., in the sense of my 'obtaining primary content'). Wittgenstein himself even authorised this translation of 'Sachverhalte'. The chain analogy occurs in the passages which strongly suggest this reading. Hence I take Wittgenstein to attempt to explain the obtaining primary contents. However, starting with proposition 2.04, Wittgenstein speaks of obtaining and non-obtaining Sachverhalte. This suggests that in these passages 'Sachverhalt' is his word for possible facts, my primary contents. In this case, the reference to incompleteness would have a different function, namely that of explaining how secondary contents can be combined. Since this exegetic uncertainty is not of systematic relevance, I shall refrain from discussing this matter in more detail.

${ }^{16}$ Armstrong has expanded on this theme in (Armstrong 2004a). 
' $a_{F}$ '. The notion of an index is strictly distinct from the notion of an argument. ${ }^{17}$ While in the Wittgensteinian option the relation between secondary contents is one between argument and function, i.e., a contingent relation, Armstrong pleads for a necessary relation between secondary contents by the one's being indexed to the other.

In virtue of its being indexed, the secondary content $a$ has a hidden complexity. The obtaining primary content of $a$ 's being $F$ is given by the existence of $a$ alone. In all possibilities in which $a$ exists, $a$ 's being $F$ also exists. This allows for $a$ 's being the truthmaker for $\langle a$ is $F>$. Or, to apply it to our pen example, the proposition $<$ the pen is black $>$ is made true by the pen insofar it is indexed to blackness.

In a sense, it is particulars which are Armstrong's truthmakers. But they are thick particulars, particulars along with their properties. These secondary contents are truthmakers in virtue of their being what I shall call 'transworld-faithful', which I define as follows:

Def.: An entity $E$ is transworld-faithful if and only if for any secondary content (or set of secondary contents) $S$ to which $E$ is tied in some world, $E$ is tied to $S$ in all worlds.

In whatever possibility $E$ exists, it is tied to $S$. The entity $E$ is faithful to $S$ across all different possibilities. It is this characteristic which makes Armstrong's $a$ (or my $a_{F}$ ) a possible truthmaker. It ensures that the predication relation between $E$ and $S$ is necessary, thus fulfilling the constraints determined by (NP).

There are several objections to Armstrong's theory. ${ }^{18}$ Firstly, $<a$ is $F>$ is, we presumed, a contingent proposition. There are possibilities in which $a$ is not $F$. How can that be, given that $a$ is supposed to be transworld-faithful? Secondly, it is a consequence of Armstrong's view that all properties of $a$ are necessary properties. Hence there is no distinction between necessary and intuitively contingent properties. Thirdly, if $a$ exists, then all primary contents concerning $a$ obtain necessarily. Facts, even 'contingent' ones, always come in packages. There are no logically independent primary contents about $a$ : Necessarily, if $<$ the pen is black $>$ is true, then $<$ the pen is in Tartu $>$ is true. But this is surely absurd.

To the first objection Armstrong answers as follows:

${ }^{17}$ The distinction between argument and index appears already in Wittgenstein's Tractatus 5.02 and the Blue Book, e.g., p. 21. In the Blue Book Wittgenstein uses the distinction in the context of discussing propositional attitudes and for slightly different, partly semantic, purposes. My usage of 'index' and 'argument' is strictly metaphysical. The terms refer to purely ontological matters.

${ }^{18}$ I shall discuss here only metaphysical objections and not, e.g., semantical objections 
What is contingent might not have existed. Suppose $a$ to be F, with $\mathrm{F}$ a universal. If this state of affairs is contingent, then it might not have existed. Suppose it had not existed. The particular $a$, the particular with all its non-relational properties, [...] would not then have existed. Something quite like it could have existed instead: a particular with all of $a$ 's properties except F. But that would have been only a close counterpart of $a$, because the intersection with $\mathrm{F}$, the partial identity with F, would be lacking. ${ }^{19}$ (Armstrong 2004b, 47)

The demanded contingency of $<a$ is $F>$ is accounted for by the idea that $a$ 's existence is contingent. If $a$ does not exist, then the proposition $<a$ is $F>$ is false. Thus the proposition $<a$ is $F>$ is only contingently true. In a possibility in which $a$ does not exist, a mere counterpart of $a$ may exist which does not have the property $F$. The proposition $<$ the pen is black $>$ is contingently true because it may be that the pen does not exist. The proposition the pen is green, although false, can be true, because a different possible world might harbour a counterpart of the pen which is green.

Taking resort to counterpart theory does also resolve (in a sense) the two other problems. We may introduce a distinction between quasi-necessary and quasi-contingent properties of $a$ in the following way. Those properties of $a$ that are shared also by all of $a$ 's counterparts are quasi-necessary properties. All other properties of $a$ are quasi-contingent. In this way, we can also introduce a quasi-independence of obtaining primary contents concerning $a$. All obtaining contents involving $a$ and its contingent properties are logically independent. The others are logically interdependent. Importantly, this strategy provides only quasi-solutions to the problems mentioned. In a strict sense, all facts concerning the one and identical $a$ are necessary and logically interdependent. We get a quasi-independence only through the quasi-identity between $a$ and its counterparts.

I think that Armstrong's refuge in counterpart theory is beset with problems. Firstly, a criticism ad hominem. Armstrong has long favoured a combinatorial theory of possibilities_-basically the idea that possibility is nothing but a possible recombination of secondary contents. If counterpart theory is right, then we simply do not have the very same secondary contents in different possibilities. This problem may be evaded by taking instead of sec-

${ }^{19}$ Actually, Armstrong's view has also a further element, which I shall note only in passing, since the complication introduced thereby is not absolutely relevant for our discussion. He adds to the quoted passage: "Equally, it now seems to me, the universal $F$ would not have existed" (Armstrong 2004b, 47). This leads to further problems, since this would mean that, once $a$ does not exist, neither would $F$ exist, leaving no room for the possibility that $b$ is $F$ when $a$ does not exist. Armstrong suggests as a remedy something like a counterpart relation for universals, thereby coming close to a view which the theory of moments, which I shall discuss in a second, seems committed to. 
ondary contents equivalence classes of counterparts of secondary contents as the basis of possible recombination. Whatever the merits of such a move may be otherwise, it surely destroys much of the initial appeal of a combinatorial theory of possibility.

Secondly, we may wonder whether a counterpart theory is well designed for the job it is supposed to do. Consider Saul Kripke's famous complaints about counterpart theory:

The counterpart of something in another possible world is never identical with the thing itself. Thus if we say 'Humphrey might have won the election (if only he had done such-and-such)', we are not talking about something that might have happened to Humphrey but to someone else, a "counterpart". Probably, however, Humphrey could not care less whether someone else, no matter how much resembling him, would have been victorious in another possible world. Thus, [the counterpart theory; W. F.] seems to me even more bizarre than the usual notions of transworld identification that it replaces. (Kripke 1981,45 , fn. 13)

So Kripke's objection is basically that counterpart theory divorces an object from its own possibilities and hence does not satisfy our intuitions.

I would phrase a related misgiving in the following way: since a counterpart of $a$ is not strictly speaking, i.e., numerically, identical to $a$, objectlanguage identity is replaced metalinguistically by a weaker relation, the counterpart relation. I find that manoeuvre dubious; replacing an identity relation by a counterpart relation is like selling a van Gogh but sending a Warhol.

Be that as it may, so far I have not come across any promising analysis of such a counterpart relation. Armstrong himself offers only two idiosyncratic constraints for such an adequate analysis, together with a rather feeble hope that such an analysis can be given:

As a "one worlder", I hope for a counterpart theory that does not invoke possible worlds other than our actual world; and as a naturalist, I hope for a theory that does not postulate actual entities over and above the spatio-temporal system. I believe that these two rather strong demands can be satisfied, but cannot discuss these issues here. (Armstrong 2004a, 145)

\section{Moments as truthmakers}

Albeit Armstrong's suggestion does provide for truthmakers, we may remain sceptical in view of the problems which accompany this solution. So let us turn to its main competitor, based on the theory of moments. The first to put them to use as truthmakers were Mulligan, Simons and Smith in their seminal paper Truth-makers. A moment is defined as follows: 
$a$ is a moment if $a$ exists and $a$ is de re necessarily such that either it does not exist or there exists at least one object $b$, which is de re possibly such that it does not exist and which is not a proper or improper part of $a$. (Mulligan et al. 1984, 294)

Let me try to give the essence of this rather difficult definition: a moment is a secondary content necessarily dependent on another secondary content which in turn is not itself a part of the former (and hence not dependent on it). Mulligan et al. give examples like the following: the-blackness-ofthis-pen, Voldemort's-last-sigh or the-handshake-between- $A$-and- $B$. Thus, moments can be monadic properties and also polyadic relations. According to the theory, moments are the truthmakers for propositions. The proposition $<$ the pen is black $>$ is made true by the-blackness-of-this-pen, and $<A$ and $B$ shake hands $>$ is made true by the-handshake-between- $A$-and- $B$.

We have met the decisive characteristic of moments already in our discussion of Armstrong's theory of partial identity. A moment is necessarily tied to that secondary content (or set of secondary contents) to which it is tied. In our case, the blackness is supposed to be necessarily tied to the pen, and the handshake is necessarily tied to the set of $A$ and $B$. Moments hence are transworld-faithful; they are indexed secondary contents. ${ }^{20}$ The secondary content blackness, understood as a moment, is necessarily tied to this very secondary content, this pen. The pen is the index of the secondary content blackness; it (partially) constitutes the entity blackness thepen $_{\text {. }}$.

As Armstrong's indexed particulars, moments are indexed secondary contents. Due to their transworld-faithfulness, they have a hidden complexity. ${ }^{21}$ There is always a hidden object involved with any moment, thus surreptitiously providing the complexity demanded of a truthmaker. A moment is nothing but an obtaining primary content in disguise. Therefore, the proposition <the pen is black> is made true by the entity blackness thepen $_{\text {. }}$ Again, the property of transworld-faithfulness gives moments the power of fulfilling (NP) and hence of being truthmakers.

How does the theory of moments deal with the various objections raised in connection with Armstrong's theory, which seem to apply here, too? Firstly, can the theory of moments account for the contingency of propositions? Yes. Moments are, according to the theory, contingent entities. The proposition $<$ the pen is black $>$ is contingent in virtue of the contingent existence

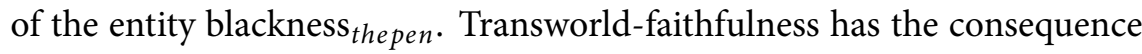
that a single moment may not belong to varying secondary contents in different possible worlds. But could it not be that a different secondary content possessed the very colour of this pen, though it does not do so in the actual

${ }^{20}$ Mulligan et al. (1984) speak of moments being "founded on" other secondary contents.

${ }^{21}$ Armstrong $(1997,117)$ speaks of states of affairs "supervening" on moments. 
world? According to our intuitions, this could be so in a literal sense. According to the theory of moments, this is not possible in a literal sense. In order to satisfy our intuitions, the moment theorist may introduce a counterpart theory of moments, which then could also be used to answer the second objection and to make a distinction between necessary and contingent properties.-Albeit this is a viable option, a counterpart theory for moments commits us, of course, to the same structural problems as the counterpart theory for particulars.

Mulligan, Simons and Smith do not clearly commit themselves ${ }^{22}$, but usually moments are also thought to have a second important characteristic, namely that of being particularised. Accordingly, a moment is tied to a single secondary content (or to a single set of secondary contents, in the case of polyadic relations). The blackness is tied to a single secondary content only, namely, to the pen. And the handshake is tied to a single set of secondary contents, the set of $A$ and $B$. Moments then are-insofar as they are properties-not universals; they are particularised properties; they are tropes.

I shall say that particularised moments are "innerworld-faithful", which I define as follows.

Def.: An entity $E$ is innerworld-faithful if and only if there is exactly one secondary content (or set of secondary contents) which is tied to $E$ in a single possible world.

It should be noted that this characteristic is logically independent of the characteristic of transworld-faithfulness. A secondary content may be tied to only a single other secondary content without being necessarily tied to it. This blackness may be tied perhaps to this pen only, without being necessarily tied to it. Innerworld-faithfulness does not imply transworld-faithfulness. Conversely, it may be that this blackness is necessarily tied to this pen, but that it is tied not only to this pen, but also to that pen, this shirt, etc. Blackness may be necessarily tied to many objects, and hence be a "universal." It may be transworld-faithful, but innerworld-promiscuous.

If transworld-faithfulness and innerworld-faithfulness are logically independent characteristics, and the former suffices for a solution to the truthmaker problem, why demand that moments are innerworld-faithful at all? The deeper motivation lies, I think, in a certain nominalistic tendency of the participants in the discussion. Innerworld-faithfulness denies moments

\footnotetext{
${ }^{22}$ The authors repeatedly cite philosophers proposing individualised moments, e.g., in (Mulligan et al. 1984, 297, 310). But they also proclaim to be "realists in respect to moments" (Mulligan et al. 1984, 299), having earlier and somewhat puzzlingly explained realism to be the theory that substances and moments are universals.
} 
the status of universals and conceives them to be tropes instead. Yet, in the present context, this characteristic has further advantages. It avoids logical interdependence of contingent facts even without appeal to counterpart theory. Suppose moments to be transworld-faithful but not innerworldfaithful. The consequence would be that, given that this pen and this shirt are black, this pen and this shirt would both have to be black once the blacknessmoment existed-blackness would be indexed to both the pen and the shirt. The consequence would hence be that the truth-values of $<$ the pen is black $>$ and $<$ the shirt is black $>$ would be interdependent. If the one proposition were true, then by necessity the other would be true, too. This consequence is surely not acceptable. Whether the pen is black is logically independent of the colour of this shirt. Once we demand moments to be innerworldfaithful, however there are no different obtaining primary contents containing the same moment. Thus, the problem of logical interdependence is avoided from the very start. Even with transworld identity for moments logical independence of the kind desired could be guaranteed.

Innerworld-faithfulness solves some problems, but it invites new ones. It has the consequence that two objects never have, because they cannot have, the very same property. There are no properties shared by different particulars; there are no universals. If two patches, $a$ and $b$, are said to be black, they have, according to this view, literally different properties, namely the different moments the-blackness-of- $a$ and the-blackness-of- $b$. But how could that be squared with our intuitions that we are dealing here with the very same property, as when we say ' $a$ and $b$ are both black'? The answer can only lie in something like an innerworld-counterpart theory that determines which moments are "the same." Of course the objections which apply to the (transworld-)counterpart theory apply mutatis mutandis also in the present case. Does such a substitute for our intuitive concept of identity really suit our intuitions? If somebody has stolen a writer's ideas, why should the writer-or his lawyers-care? After all, the thief's ideas are not identical (in the strict, numerical sense) to the writer's ideas.

This objection is analogous to Saul Kripke's objection against the (transworld-)counterpart theory. But perhaps we can dispense with this criticism. The minimal requirement for such an innerworld-counterpart relation is that it should be explained to us. So far I have not seen anything coming close to satisfying this requirement.

\section{A comparison of Wittgenstein, Armstrong and the theory of moments}

Let me now give a structural comparison of the three theories discussed. They all try to provide for truthmakers without appealing to a combination 
relation. They deny $\left(\mathrm{C}_{1}\right)$, the principle that in order for there to be combination, there must also be a combinator. Wittgenstein's solution is based on the notion of incompleteness, but cannot provide truthmakers in the first place. Both Armstrong's theory and the theory of moments involve the property of transworld-faithfulness in order to make instantiation necessary. In this way these theories successfully account for truthmakers, i.e., entities fulfilling the constraints made explicit in (NP). The necessitation demanded of a truthmaker is introduced by the necessity of predication or, more generally, combination. The basic difference between the two models lies in the type of indexed secondary content chosen as the bearer of the characteristic of transworld-faithfulness. ${ }^{23}$ Moment theory chooses properties as indexed secondary contents, Armstrong chooses particulars as indexed secondary contents.

The notion of transworld-faithfulness applied to secondary contents solves the truthmaker problem, but it creates new problems. The ontologically most important ones are the following: the problems of accounting for contingency, for logical independence of contingent facts, and of making the distinction between contingent and necessary obtaining primary contents. In reaction to them, the indexed secondary contents are themselves deemed to be contingent objects, demanding then some sort of (transworld-)counterpart theory for the indexed secondary contents. Most moment theorists go even further and claim their indexed secondary contents to be innerworldfaithful as well-thereby giving a straightforward solution to the problem of logical independence, but also inviting new problems.

\section{Indexed combination}

According to the discussion so far, we seem to be caught in a dilemma. Predication must be necessary in order to fulfil (NP). This can be ensured only through indexing. But the indexing of secondary contents has counterintuitive consequences, and hence is to be avoided.

Can we keep secondary contents index-free and still make combination necessary? Not with an ontology of secondary contents alone. But expand ontology to cover combination relations, and things will turn out just right. I suggest that we should not index secondary contents but rather the combination relations. I assume the existence of combination relations and claim them to be transworld-faithful. My strategy is essentially Strawson's; his "non-relational ties" are to be explained as indexed combination relations: I shall affirm principle $\left(\mathrm{C}_{1}\right)$ and attempt to escape $\left(\mathrm{C}_{2}\right)$, the principle that if

${ }^{23}$ Of course, if secondary contents are all on a par, as I hold, then there is no relevant difference at all. 
there is a combinator, it must itself be combined with the things it combines.

Consider the case of the proposition $\langle a$ is $F\rangle$. Assume there to be a combination relation, and assume further that the combination relation is indexed to the secondary contents $a$ and $F$. Thus, combination indexed in the right way, call it ' $\mathrm{C}_{a, F}$ ', relates $a$ and $F$ necessarily-once it (i.e. $\mathrm{C}_{a, F}$ ) exists. The secondary content $a$ is an argument for $F$, and $F$ is an argument for $a$. Thus we may still assume an ontology of (incomplete) secondary contents. But neither $a$ nor $F$ are arguments for $C_{a, F}$. Indexed combinations have no arguments. The status of arguments is reserved for secondary contents alone. Combination relations are not secondary contents. They are indexed. They have indexes and hence possess a hidden complexity; they are obtaining primary contents in disguise. In this way, they are suitable truthmakers. $C_{a, F}$ is the truthmaker for $<a$ is $F>$. The proposition $<$ the pen is black $>$ is made true by the existence of the combination relation indexed to the pen and to blackness: $\mathrm{C}_{\text {thepen,blackness }}$.

By indexing combination to (sets of) secondary contents, we get all the benefits that come with transworld-faithfulness. But how does the theory of indexed combination deal with the difficulties we have encountered in relation to the theories of indexed secondary contents? Let us discuss these problems in turn.

Firstly, to the problem of contingent propositions: I shall follow the same strategy as the theory of moments and Armstrong's theory do. The contingency of a proposition is ensured by the contingent existence of the indexed entity. Since the indexed entity is, under the present view, the combination relation, a proposition is contingent not because of the contingent existence of secondary contents, but because of the contingent existence of the combination relation. $<$ The pen is black $>$ is contingently true, because the combination relation between the pen and blackness need not exist.

Secondly, is it possible that the very same secondary contents, $a$ and $F$, figure in mere possibilities? Of course! Since secondary contents are not indexed, they may be literally identical in different possibilities concerning them. The very same secondary content is contained in different primary contents. To illustrate this point with our example, assume that the pen and blackness are combined. The very same pen might also have been combined with greenness, and the very same blackness might have been combined with a shirt. Secondary contents may remain identical throughout different possibilities. The combination relation, however, cannot. The combination relation is only in that possible world that is also actualised. Yet this is not a vice; it is a virtue. In mere possibility, there is no actuality, there is no combination relation indexed to secondary contents at all. A counterpart theory for indexed combination is not only not demanded; it would even be absurd. 
Thirdly, how does the theory of indexed combination cope with the logical independence of contingent facts? If the combination relation exists, then all primary contents in which the combination relation figures do actually obtain. If there is one combination relation for all the facts, then they all exist in exactly the same possibilities and are hence logically interdependent. The consequence would be that, e.g., the truth-values of $<$ the pen is black $>$ and of $<$ the shirt is green $>$ would be interdependent. Of course, the problem is avoided in the present conception, according to which combinations exist in the actual world only. This precludes logical interdependence of contingent facts. An independent solution, however, is obtained by assigning to the combination relation not only transworld-faithfulness, but also innerworldfaithfulness. This is what I shall do. Two facts never have a combination relation in common. The truthmaker for $<$ the pen is black $>$ is $\mathrm{C}_{\text {the pen, blackness' }}^{1}$ the truthmaker for $<$ the shirt is green $>$ is $\mathrm{C}_{\text {the shirt, greenness, }}^{2}$ and so on. Each obtaining primary content is constituted by a numerically different combination relation.

To conclude this section on prima facie problems for indexed combination, consider the question of identity of secondary contents in different obtaining primary contents. The very same secondary contents may be indexes of different combination relations and hence be constituents of different primary contents. As in the previous "problem" cases, the theory of indexed combinations simply abides by our intuitions straightaway.

Indexed combinations are much like particularised moments. They are transworld-faithful and innerworld-faithful. The only difference is that the bearers of these characteristics are the combination relations, not secondary contents. Our intuitions demand innerworld- and transworld-identity of secondary contents. Since these remain free of transworld- and innerworldfaithfulness, we simply do not run into conflicts with our intuitions. Thus the theory of indexed combinations has all the virtues of the theory of particularised moments without any of its drawbacks. Indexed combinations are just what we need.

\section{Conclusion}

I have argued that truthmakers are indexed combinations. They are entities which are not secondary contents. It remains a task for the future to better understand this expanded ontology.

My thesis was here restricted to positive, predicative, elementary propositions. A full theory must take a stance on other kinds of propositions, too. The question has to be answered whether the other kinds of propositions must have truthmakers too, and what these truthmakers should look like.

I have not, in this essay, discussed the problem of nonsymmetric rela- 
tions. It may be that Tom loves Jenny but Jenny does not love Tom. This means that we need to distinguish obtaining primary contents with exactly the same secondary contents. The demonstration that and how the theory of indexed combinations can cope with this problem must, like so many other things, be reserved for another occasion.

\section{Acknowledgements}

The central thesis developed in a discussion with Alexandra Zinke. She also provided me with useful comments on the penultimate draft of this paper. Remaining mistakes are, of course, my own. I also had the opportunity to present the core points of this paper to the participants of a workshop on 'Truth' at the University of Tartu in October 2007. I am grateful for the suggestions that I received. This paper draws on results from an ongoing research project commissioned by the Landesstiftung Baden-Württemberg (Germany). I am very much indebted for the support provided.

\section{Bibliography}

Armstrong, D. (1997). A world of states of affairs, Cambridge University Press, Cambridge.

Armstrong, D. (2004a). How do particulars stand to universals?, in D. W. Zimmerman (ed.), Oxford Studies in Metaphysics, Vol. 1, Clarendon Press, Oxford, pp. 139-154.

Armstrong, D. (2004b). Truth and truthmakers, Cambridge University Press, Cambridge.

Dodd, J. (2000). An identity theory of truth, Macmillan Press, Basingstoke.

Frege, G. (1994). Über Begriff und Gegenstand, in G. Patzig (ed.), Gottlob Frege: Funktion, Begriff, Bedeutung, Vandenhoeck \& Ruprecht, Göttingen, pp. 66-8o.

Freitag, W. (2005). The topology of formal philosophy, $\mathrm{PhD}$ thesis, University of Konstanz.

Horwich, P. (1998). Truth, Basil Blackwell, Oxford.

Kripke, S. (1981). Naming and necessity, Blackwell, Oxford.

MacBride, F. (2005). The particular-universal distinction: A dogma of metaphysics?, Mind 114: 565-614.

Mulligan, K., Simons, P. and Smith, B. (1984). Truth-makers, Philosophy and Phenomenological Research 44: 287-321. 
Rodriguez-Pereyra, G. (2005). Why truthmakers?, in H. B. J. Dodd (ed.), Truthmakers: The contemporary debate, Clarendon Press, pp. 17-31.

Strawson, P. F. (1959). Individuals: An essay in descriptive metaphysics, Routledge, London, New York.

Valicella, W. F. (2000). Three conceptions of states of affairs, Noûs 34: 237259.

Wittgenstein, L. (1922). Tractatus logico-philosophicus, Routledge, London, New York.

Wittgenstein, L. (1973). Letters to Ogden, Blackwell, Oxford. 